\title{
The Effect of Fabric Structural Geometry on Thermal Transfer Performance in Sportswear
}

\author{
Sertaç Güney ${ }^{*}$, Hilal Balcı², İbrahim Üçgül ${ }^{3}$ \\ ${ }^{1}$ Selçuk University, Faculty of Architecture and Design, Textile Design and Produciton Department, Konya, Turkey (ORCID: 0000-0002-9301-0026) \\ 2 Istanbul Arel University Vocational School, Department of Fashion Design, İstanbul, Turkey (ORCID: 0000-0001-5442-8860) \\ 3 Süleyman Demirel University, Engineering Faculty, Textile Engineering Department, Isparta, Turkey (ORCID: 0000-0001-9794-0653)
}

(İlk Geliş Tarihi 4 Ekim 2019 ve Kabul Tarihi 8 Kasım 2019)

(DOI: $10.31590 /$ ejosat.629477)

ATIF/REFERENCE: Güney, S., Balcı, H. \& Üçgül, İ. (2019). The Effect of Fabric Structural Geometry on Thermal Transfer Performance in Sportswear. Avrupa Bilim ve Teknoloji Dergisi, (17), 711-717.

\begin{abstract}
Especially for textiles, which contain open structure pores, airflow carrying heat energy transfers from one side to another side by conduction and convection. Convective heat transfer plays a very important role in thermal transfer performance of textiles due to its porous structure. Compression sportswear are generally produced from knitted porous stretch fabrics, which get extended on wearing and remain in the extended state. Since they are worn next to skin and are direct contact with the body surface, their thermal comfort properties are effective on overall clothing comfort. Perhaps the greater contact of the garment to the skin together with the constant airflow can transfer the heat better from the body to the environment. Most of the well-known auxetic materials possess porous microstructures and the sizes of the pores of auxetic materials can vary during the compressive and tensile deformation. In this study, an investigation has been made to evaluate the auxetic effect on the thermal transfer performance of clothing. Two type fabrics having the very similar fabric properties but different knitting structures were provided from the market and producer. While one has an auxetic structure, the other has a standard warp knitting structure commonly used in market. As permeability and porosity are strongly related to each other, we compared air permeability of fabrics in extended state considering the fabric extension results taken from virtual avatar having the same body measurements as subjects in 3D simulation. Fabric surface temperature changes on different clothed body parts investigated by an infrared thermal camera and analysed in thermal camera software (Flir Tools) for thermal transfer performance according to the wearing protocol.
\end{abstract}

Keywords: Fabric structural geometry, auxetic structure, thermal comfort, porous structure

\footnotetext{
* Sorumlu Yazar: Selçuk University, Faculty of Architecture and Design, Textile Design and Produciton Department, Konya, Turkey, ORCID: 00000002-9301-0026, sertac.guney@ selcuk.edu.tr
} 


\section{Introduction}

Compression sportswear has grown immensely and become attractive in personel or team sports in recent years. A pleasing contact perception, reasonable pressure profile and optimum thermal-moisture properties are fundamental to promote comfort and physical performance and health to the athletes since these garments are typically designed to directly maintain contact with athlete's body [1]. Compression garments elongates up to $10 \%$ in lenght and $60 \%$ in width when worn, depending on the variations in body circumference. This stretch also changes the loop shape, density, thickness of fabric and also porosity. All these changes are expected to affect significantly the comfort behaviour of fabrics [2]. Heat and mass transfer through the garment is mostly dependent on the change in the contact area and porosity. Sport garments are at the interface between the human body and the environment and therefore modify the heat and mass transfers occurring at the skin surface. Clothing interacts with physiological and physical processes impacting skin temperature that can be assessed by infrared thermography. The assessment of sport garments, specifically their impact on the skin using thermography, enables great advances in the field of garment design and its consequence on sport performance and thermal comfort [3]. Conventional materials generally have positive poisson's ratio, contracting laterally when stretched and expanding laterally when compressed. Auxetic materials are quite the opposite, they exhibit a negative poisson's ratio and expand laterally when stretched and contract laterally when compressed. Most of the well-known auxetic materials possess porous microstructures and the sizes of the pores of auxetic materials can vary during the compressive and tensile deformation [4]. In the scope of textiles, auxetic fabrics have been widely researched and obtained with different structural units, such as fabric with negative poisson's ratio [5-9]. Re-entrant structure is the most commonly used auxetic structure in designing, manufacturing and researching fields. Basically the auxetic property is achieved by unfolding the re-entrant units as shown in Figure 1-a [10].

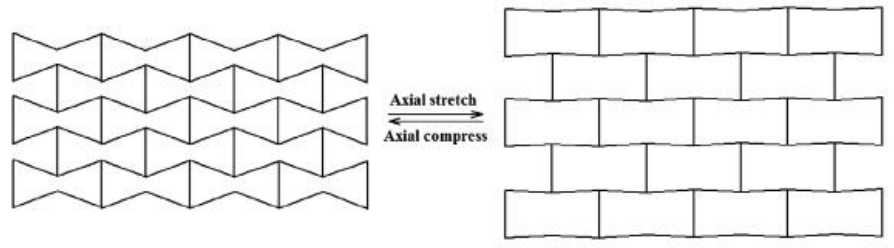

(a)

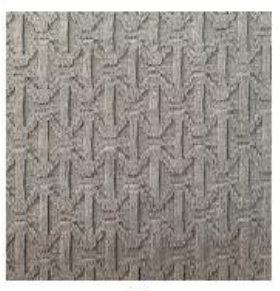

(b)

Figure 1. Re-entrant hexagonal structure (a) and auxetic fabric structure (b) [5].

As seen in Figure 1-a, under axial stretch the pore size changes in structure. Utilizing this behavior, these structures may have a significant potential for sportswear. With the development of auxetic materials, many results have been achieved among which knitted fabrics with negative poisson's ratio and their mechanical behaviours have been investigated [5-9,11-12]. However, there is no study about the influence of auxetic effect on thermal transfer performance of fabrics. In this study, the performances of auxetic warp knitted t-shirt and standard warp knitted t-shirt commonly used in sports market were compared.

\section{Materials and Methods}

\subsection{Materials}

Two type fabrics having the very similar fabric properties but different knitting structures were provided from the market (Underarmour Inc.) and producer. While one has an auxetic structure, the other has a standard warp knitting structure mostly used in market. The fabric properties were given in Table 1 .

Table 1. Fabric properties

\begin{tabular}{|l|l|l|}
\hline Fabric Code & A & B \\
\hline $\begin{array}{l}\text { Fibre Composition } \\
\text { Yarn Counts }\end{array}$ & $\begin{array}{l}\text { 80\% PA 20\% Elastane } \\
55 \mathrm{D} \text { PA / 70D Spandex }\end{array}$ & $\begin{array}{l}80 \% \text { PA 20\% Elastane } \\
40 \mathrm{DA} / 70 \mathrm{D} \text { Spandex }\end{array}$ \\
\hline Fabric Structure & Auxetic warp knitted & Warp knitted \\
\hline Fabric Mass $\left(\mathrm{g} / \mathrm{m}^{2}\right)$ & 240 & 240 \\
\hline Fabric Thickness $(\mathrm{mm})$ & 0.78 & 0.65 \\
\hline Air Permeability $\left(\mathrm{l} / \mathrm{m}^{2} / \mathrm{s}\right)$ & 942.1 & 372.8 \\
\hline $\begin{array}{l}\text { Thermal Resistance } \\
\left(\mathrm{m}^{2} \mathrm{~K} / \mathrm{W}\right)\end{array}$ & 13.02 & 8.54 \\
\hline
\end{tabular}


Microscopic views of fabric structures were shown in Figure 2.

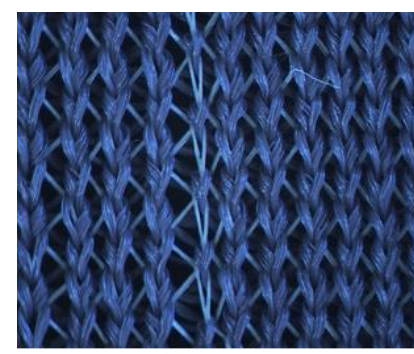

(a)

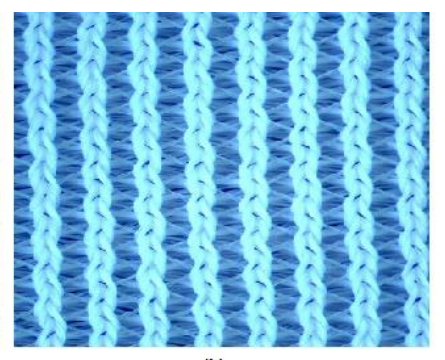

(b)

Figure 2. Microscopic views of fabric A (a) and B structures (b)

The loop density of fabric B is higher than the one of fabric A so that Fabric B is more compact and has less air permeability. In fabric A, to give a re-entrant relief shape in knitting, different loop movements had been used so that the fabric thickness is higher than fabric B. For thermal transfer performance test, T-shirts with sleeve in the same style as the t-shirt provided from market (Underamour Inc.) were produced for wear trials.

\subsection{Methods}

In order to determine the fabric extensions on different garment sections, KES-F (Kawabata evaluation system for fabrics) measurements were input into the simulation and the fabric extension maps were obtained (Figure 3).

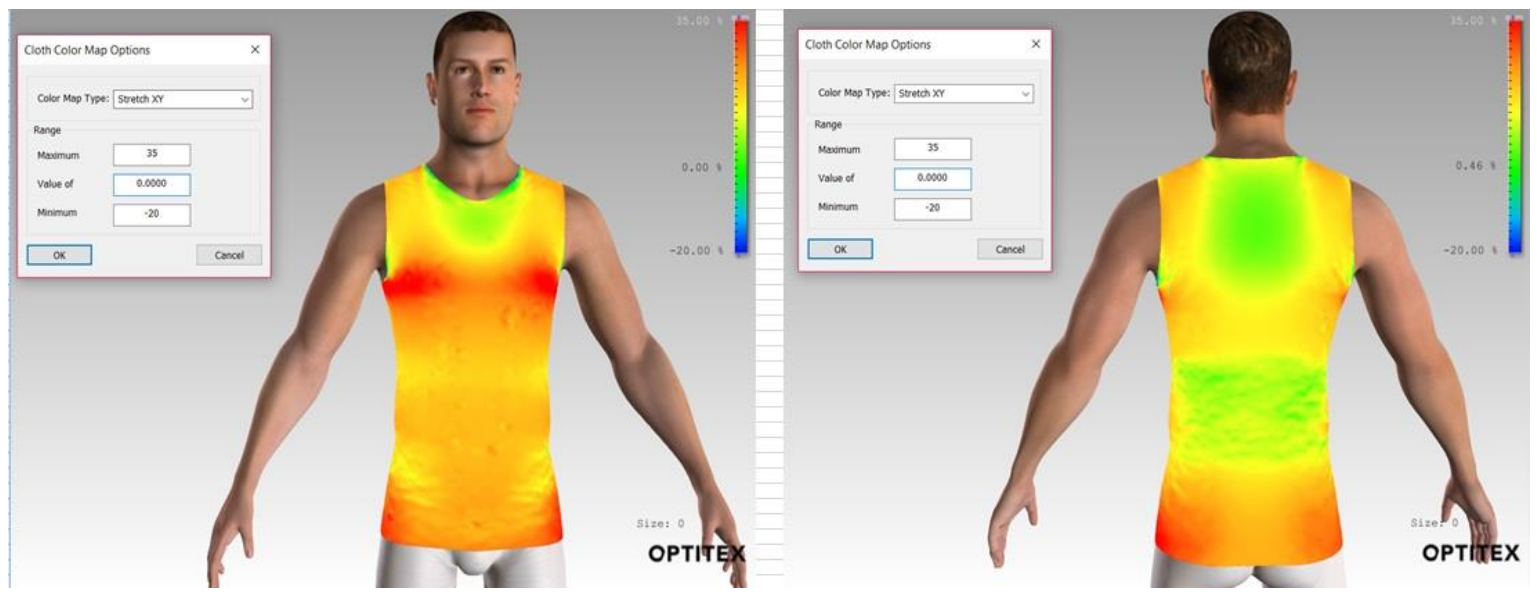

Figure 3. The fabric extension maps

In second part, The temperature distributions of clothing outer surface was investigated by an infrared thermal camera (Flir E40 with $0.07^{\circ} \mathrm{C}$ thermal sensitivity). The tests were conducted in a performace room at a temperature of $20 \pm 2{ }^{\circ} \mathrm{C}$, relative humidity of $50 \pm 5 \%$. Subjects were asked to wear the tshirts and stand on footprints keeping the arm straight. The locations of infrared thermal camera and body posture were kept constant during the measurements. The infrared thermal measurements included two steps, first subjects were asked to wear t-shirts and body postures were photographed then subjects rested for ten min wearing tshirts and body postures were photographed again. The clothing surface temperatures were then analyzed by thermal imaging software (Flir Tools) to get the average temperatures of sections on bust, waist and hip lines. To measure the surface temperatures of clothing, eight measuring areas were drawn on the frontal (E1-E2-E3-E4) and rear (E1-E2-E3-E4) infrared photos of upper body. The assumed extension values according to the extension maps in measuring areas were shown in Table 2. 
Table 2. The extension values in extension maps

\begin{tabular}{|l|l|l|}
\hline \multirow{4}{*}{ Frontal } & \multicolumn{2}{|l|}{ Results in extension maps } \\
\cline { 2 - 3 } & E2 & $20 \%$ \\
\cline { 2 - 3 } & E3 & $30 \%$ \\
\cline { 2 - 3 } & E4 & $10 \%$ \\
\hline \multirow{4}{*}{ Rear } & E1 & $30 \%$ \\
\cline { 2 - 3 } & E2 & $20 \%$ \\
\cline { 2 - 3 } & E3 & $40 \%$ \\
\cline { 2 - 3 } & E4 & $10 \%$ \\
\hline
\end{tabular}

As a compression garment extends in width as well as length when worn, the constructional and air permeability properties were measured at relaxed condition and also in different extended conditions. For measuring the extended fabric samples, a $16 \times 16 \mathrm{~cm}^{2}$ frame was prepared. $10 \mathrm{~cm} \times 10 \mathrm{~cm}$ square was marked on the relaxed fabric mounted on the frame at a given extension (10-20-3040\%). In fabric extension maps, the max extension is determined as 35\%. For this reason, it was determined that the measurements made under the maximum extension of $40 \%$ would be sufficient. Negative poisson's ration and air permeability were measured by extending the fabric on the frame. Fabric motions were recorded using a 13MP camera during the whole tension process until $40 \%$ extension and image process software DIGIMIZER was utilized to calculate negative poisson's ratio of the structure.

Air permeability of relaxed and extended fabric samples was tested according to EN ISO 9237 standard using FX 3300. Average of at least 10 readings was taken.

\section{Results and Discussion}

The Poisson's ratio was calculated from Equation (1) below by using data obtained from image software (Figure 4). The lowest value -0.703 of negative poisson's ratio was achieved when exposed to the strain of $8 \%$ then the values increased and it turned to positive poisson's ratios.

$$
\nu=-\varepsilon x / \varepsilon y
$$

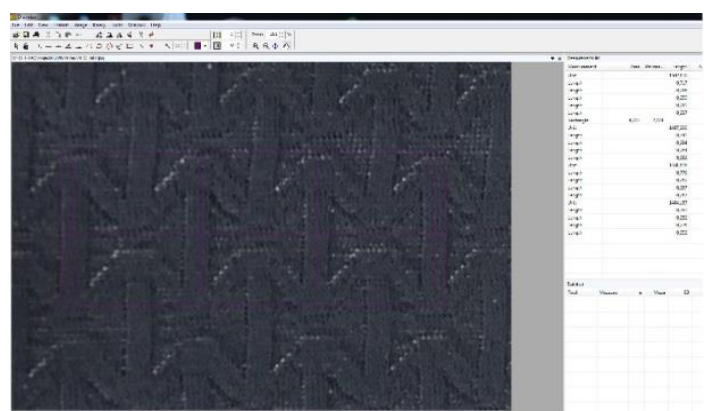

Figure 4. Measuring the poisson's ratio of fabric from image software 
Air permeability values of the fabrics at various extension levels in bias direction were shown in Figure 5. Both of fabrics reached to the similar air permeability value at $40 \%$ extension level. Fabric A showed a stable increasing in air permeability values. Fabric B showed a little bit quick increase in air permeability values.

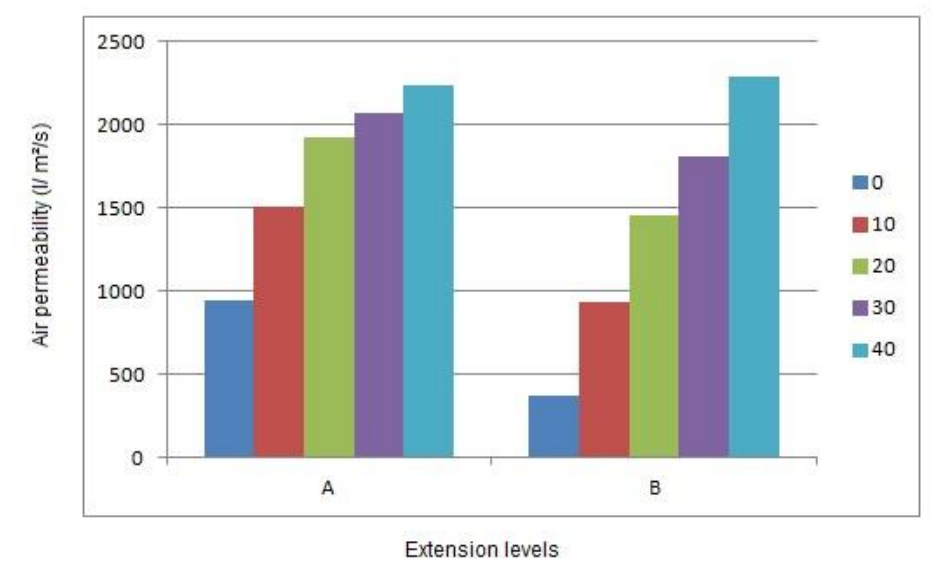

Figure 5. Air permeability values at various extension levels in bias direction (10-20-30-40\%)

Air permeability values of the fabrics at various extension levels in wale direction were shown in Figure 6. Auxetic effect can be seen in this direction. It proved the stability in air permeability in more visible. In fabric B, the value variations at various extensions are higher and it could cause a disadvantage in thermal transfer performance. Because an optimum air permeability levels should be defined for better body thermal balance.

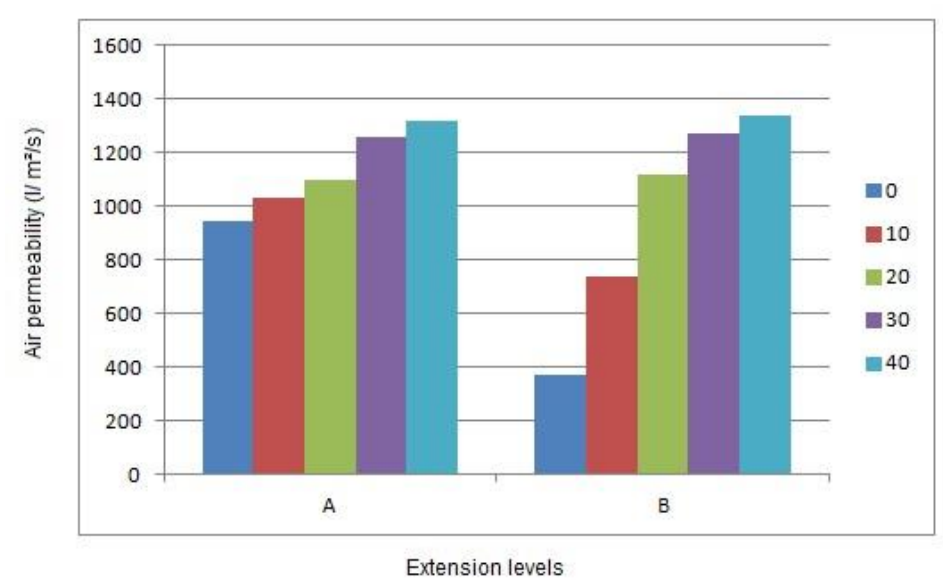

Figure 6. Air permeability values at various extension levels in wale direction (10-20-30-40\%)

The differences between clothing surface temperature and body temperature in initial and after 10 minutes wear trials were investigated by thermal imaging software (Figure 7). 


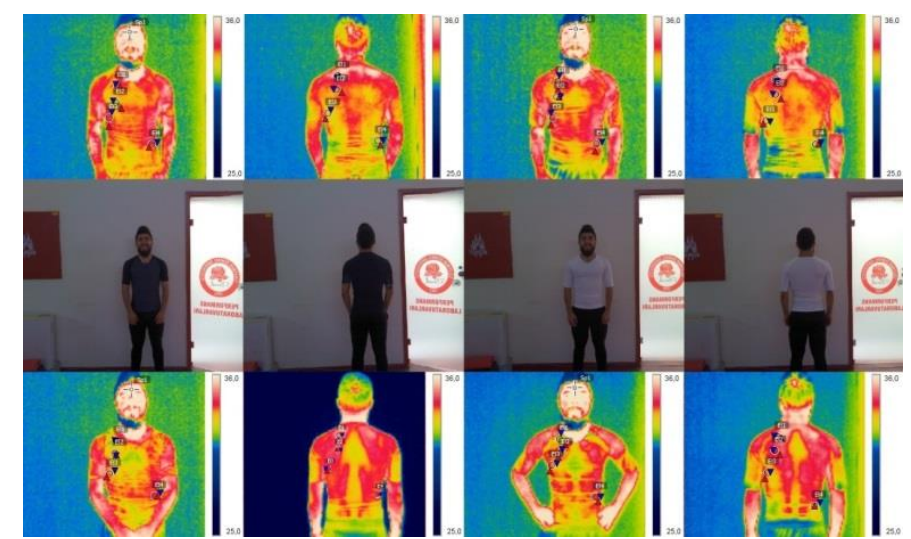

Figure 7. Thermal camera shots of initial wear trial (top row) and after 10 minutes (bottom line)

The results showed that the temperature differences of fabric B on all frontal and rear sections were higher. It can be said that fabric $\mathrm{A}$ is more capable in heat transfer due to its stable structure under extension (Figure 8).
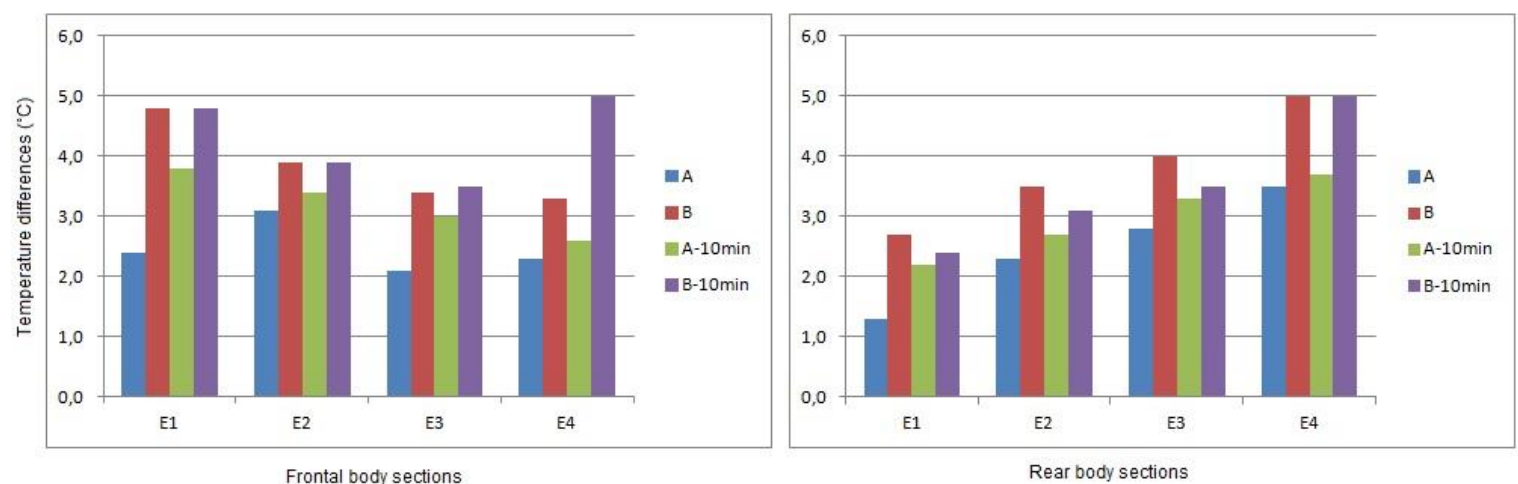

Figure 8 . The differences between clothing surface temperature and body temperature in initial and after 10 mins wear trials

\section{Conclusions}

Nowadays consumers like better the final products having not only basic features and also multifunctional and aesthetic features. So manufacturers need to research and invest on new industrial skills for brand new products to meet the consumers' expectations. Design and production of auxetic garment using conventional yarns are still challenging and also interesting but the development of auxetic structures in knitted fabric are very limited. As the porosity is effective for heat transfer and permeability and porosity are strongly related to each other, we compared air permeability of fabrics in extended state. The results show that auxetic effect brings stability in air permeability thanks to its stable changing structure and it could have an advantage in thermal transfer performance. And also stable pore openings bring advantage in heat flux and restrain the excessive heat loss. In next study, the effect of different auxetic structures on thermal transfer performance will be investigated.

\section{References}

[1] Liu, R., Little, T. and Williams, Jr., Compression Form-fitted Athletic Wear: Pressure Performance, Moisture Management Properties under Different Tension Ratios and Corresponding Psychophysical Responses, Fiber and Polymers, (2014), Vol.15 (3), pp.632-644.

[2] Gupta, D., Chattopadhyay, R. and Bera, M., Comfort properties of pressure garments in extended state, Indian Journal of Fibre\&Textile Research, (2011), Vol.36, pp.415-421.

[3] D Fournet, D. and Havenith, G., (2017), Assessment of Sport Garments Using Infrared Thermography, Application of Infrared Thermography in Sports Science, Chapter 7, pp 159-183.

[4] Ma, P., Chang, Y., Boakye, A. and Jiang, G., (2017), Reviw on the knitted structures with auxetic effect, The Journal of The Textile Institute, Vol.108, 6, 947-961.

[5] Hu H, Wang Z, Liu S (2011) Development of auxetic fabrics using flat knitting technology. Text Res J 81: 1493-1502.

[6] Liu Y, Hu H, Lan JKC, Liu S (2010) Negative Poisson's raito weft-knitted fabrics. Text Res J 80: 856-863.

[7] Glazzard M, Breedon P (2013) Weft-knitted auxetic textile design. Physica Status Solidi B 251: $267-272$.

[8] Ugbolue SC, Kim YK, Warner SB, Fan Q, Yang C, et al. (2012) Engineered warp knit auxetic fabrics. Text Sci Eng 2. 
[9] Alderson K, Alderson A, Anand S, Simkins V, et al. (2012) Auxetic warp knit textile structures. Physica Status Solidi B 7: 13221329.

[10] Gibson,L. J., Ashby , M.F., Schajer, G.S. and Robertson, C.I., (1982), The mechanics of two-dimensional cellular materials, Proceedings of the Royal Society of London A: Mathematical, Physical and Engineering Sciences, 382, 25-42.

[11] Ma, P., Chang, Y., \& Jiang, G. (2015). Design and fabrication of auxetic warp-knitted structures with a rotational hexagonal loop. Textile Research Journal.

[12] Wang, Z., \& Hu, H. (2014a). 3D auxetic warp-knitted spacer fabrics. physica status solidi (b), 251, 281-288. 